\title{
ESENSI LESSON STUDY DI ERA 4.0
}

\author{
Dianna Ratnawati \\ Pendidikan Teknik Mesin, Universitas Sarjanawiyata Tamansiswa' Yogyakarta \\ Email: dianna.ratnawati@ustjogja.ac.id
}

\begin{abstract}
Collaborative and sustainable actions carried out by a group of teachers/lecturers through lesson study with an information and communication technologies approach can meet the needs of the world of education in era 4.0. This study aims to analyze the impact of the application of lesson study in learning activities on technical measurement on mechanical engineering students of the Universitas Sarjanawiyata Tamansiswa. The research method uses lesson research with a qualitative approach. The applied lesson study model adopts Saito et al. (2005), in which its implementation consists of 2 cycles, each cycle includes the stages of plan, do, and see. The learning media used are a digital book, e-learning using Edmodo, Toyota $7 k$ engine stand, handphone, cylinder block, clutch, differential, dial gauge, cylinder gauge, vernier caliper and micrometer. The sample selected amounted to 30 students and involved two observers in each cycle. The results of this study indicate that the essence of lesson study has an impact on increasing student activity by $40 \%$ in cycle 1 and $34 \%$ in cycle 2. The lesson study also has an effect on improving the quality of the lecturer's evaluation on the students' learning outcomes.
\end{abstract}

Keywords: lesson study, 4.0 era, learning

\begin{abstract}
ABSTRAK
Tindakan kolaboratif dan berkelanjutan yang dilakukan sekelompok guru/dosen melalui lesson study dengan pendekatan information and communication technologies dapat memenuhi kebutuhan dunia pendidikan di era 4.0. Penelitian ini bertujuan untuk menganalisis dampak penerapan lesson study dalam kegiatan pembelajaran pengukuran teknik pada mahasiswa pendidikan teknik mesin Universitas Sarjanawiyata Tamansiswa. Metode penelitian menggunakan lesson research dengan pendekatan kualitatif. Model lesson study yang diterapkan mengadopsi dari Saito dkk (2005), dimana dalam pelaksanaannya terdiri dari 2 siklus dengan tahapan tiap siklusnya meliputi plan, do, dan see. Media pembelajaran yang digunakan adalah digital book, elearning melalui edmodo, engine stand toyota 7k, handphone, blok silinder, kopling, gardan, dial gauge, cylinder gauge vernier celiper dan mikrometer. Sampel yang dipilih berjumlah 30 mahasiswa dengan melibatkan 2 observer pada tiap siklusnya. Hasil penelitian ini menunjukkan bahwa esensi lesson study berdampak pada peningkatan keaktifan siswa sebesar $40 \%$ pada siklus 1 dan meningkat 34\% pada siklus 2, selain itu berdampak pada peningkatan kualitas evaluasi dosen terhadap hasil belajar mahasiswa.
\end{abstract}

Kata kunci: lesson study, era 4.0, pembelajaran

\section{PENDAHULUAN}

Dalam rangka meningkatkan mutu pendidikan di Indonesia diperlukan upaya yang serius untuk meningkatkan kualitas tenaga pendidik. Seorang guru/dosen memiliki peran yang paling besar dalam upaya inovasi serta peningkatan mutu pendidikan melalui inovasi dalam proses pembelajaran. Terlebih tuntutan di era revolusi industri 4.0 adalah guru/dosen harus dapat memanfaatkan media digital dalam mentransfer informasi dan pengembangan media pembelajaran. Suatu model pembinaan guru/dosen untuk mencapai kualitas pembelajaran di sekolah adalah lesson study. Lesson study adalah "model pembinaan profesi pendidik melalui pengkajian pembelajaran secara kolaboratif dan berkelanjutan berlandaskan prinsip-prinsip kolegalitas dan mutual learning untuk membangun komunitas belajar" (Hendayana dkk, 2006: 10). Dalam pelaksanaan program pembelajaran di Lembaga Pendidikan Tinggi Keguruan (LPTK), Lesson study dapat digunakan sebagai model bimbingan mengajar bagi mahasiswa. Di sisi lain, Lesson study dipandang dapat mendorong 
inovasi pembelajaran di sekolah/perguruan tinggi karena semua pihak terlibat dan berkonsentrasi ke arah perbaikan.
Lewis, Perry, dan Hurd 2003, (dalam Hendayana, dkk. 2006) mengemukakan keunggulan atau kelebihan lesson study seperti dalam diagram berikut.

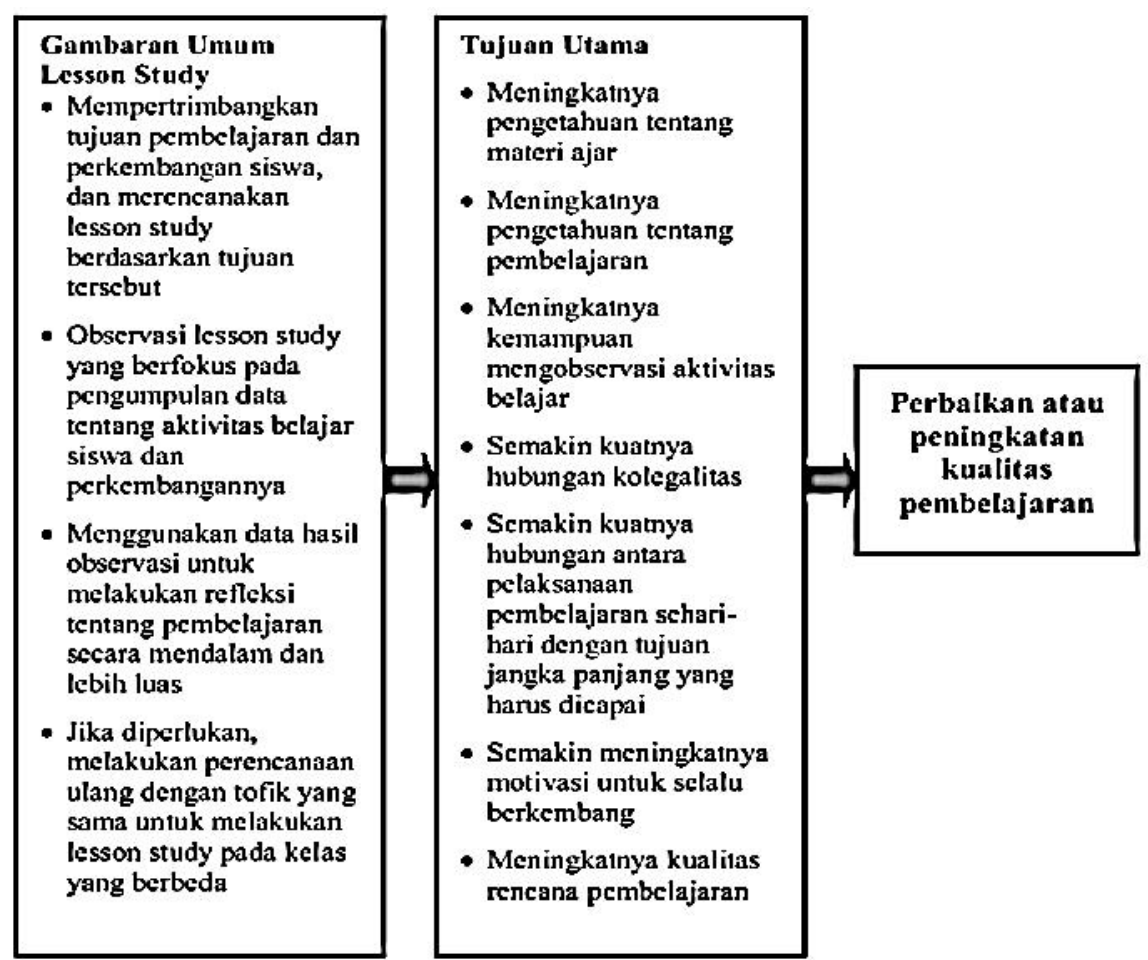

Gambar 1. Keunggulan dan Kelebihan Lesson study

\begin{tabular}{lccr}
\multicolumn{1}{c}{ Lesson } & study & merupakan & bentuk \\
penelitian & praktis & guru/dosen & dalam \\
menyelidiki & masalah & pengajaran & dan
\end{tabular} pembelajaran di kelas mereka sendiri (Zeichner \& Noffke, 2001 dalam Cerbin dan Kopp, 2006). Hal ini dapat menjadi metode untuk menghasilkan tidak hanya praktisi pengetahuan tetapi juga pengetahuan professional.

Siklus lesson study. Ada berbagai variasi tahapan atau langkah dalam pelaksanaan lesson study pada perkembangan implementasinya. Lewis (2002) menyarankan ada enam tahapan dalam awal mengimplementasikan lesson study di sekolah, yaitu: (1) membentuk kelompok lesson study, (2) memfokuskan lesson study, (3) menyusun rencana pembelajaran, melaksanakan pembelajaran di kelas dan mengamatinya (observasi), (5) refleksi dan menganalisis pembelajaran yang telah dilaksanakan, (6) merencanakan kegiatan pembelajaran tahap selanjutnya. Richardson (2006) menuliskan ada 7 tahap atau langkah yang termasuk dalam lesson study, yang masih mirip deng Lewis, yaitu: (1) membentuk tim lesson study, (2) memfokuskan lesson study, (3) merencanakan pembelajaran, (4) persiapan untuk observasi, (5) melaksanakan pembelajaran dan observasinya, (6) melaksanakan diskusi pembelajaran yang telah dilaksanakan (refleksi), (7) merencanakan pembelajaran untuk tahap selanjutnya.

Dalam implementasi lesson study yang dilakukan oleh IMSTEP-JICA di Indonesia, Saito, dkk (2005) mengenalkan lesson study yang berorientasi pada praktik. Oleh karena itu, penelitian lesson study memiliki 3 tujuan pokok, yakni: (1) merencanakan pembelajaran dengan penggalian akademis pada topik dan alat-alat pembelajaran yang digunakan, yang 
selanjutnya disebut tahap Plan, (2) melaksanakan pembelajaran yang mengacu pada rencana pembelajaran dan alat-alat yang disediakan, serta mengundang rekan-rekan sejawat untuk mengamati. Kegiatan ini disebut tahap Do, (3) melaksanakan refleksi melalui berbagai pendapat/tanggapan dan diskusi bersama pengamat/observer. Kegiatan ini disebut tahap See.

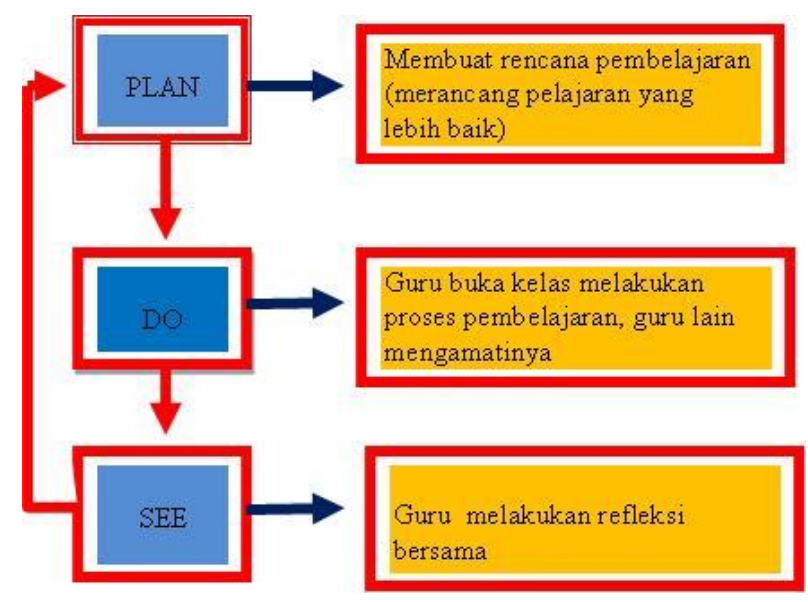

Gambar 2. Lesson study Cycle

Hasil maksimal akan diperoleh apabila seluruh tahapan yang ada dalam lesson study dilaksanakan secara utuh dan berkesinambungan, keberhasilan lesson study dapat dilihat pada dua aspek pokok, yaitu, perbaikan pada praktek pembelajaran oleh guru/dosen, dan meningkatnya kolaborasi antar guru/dosen.

\section{METODE}

Metode penelitian ini menggunakan lesson research dengan pendekatan kualitatif. Model lesson study mengadopsi dari Saito dkk (2005) dengan dibatasi pada 2 siklus.Materi yang dipilih pada siklus 1 adalah pengukuran teknik menggunakan alat ukur dial gauge dan pada siklus 2 menggunakan alat ukur cylinder gauge dan vernier caliper/jangka sorong, mikrometer. Media pembelajaran yang dipilih berupa engine stand kijang $7 \mathrm{k}$, handphone, alat ukur dial gauge, cylinder gauge, vernier caliper, dan blok silinder. Sampel dlaam penelitian ini dipilih satu kelas yang berjumlah 30 mahasiswa penedidikan teknik mesin semester 3 tahun ajaran 2018/2019. Jumlah observer yang dilibatkan dalam tiap siklusnya adalah 2 orang dosen. Adapun instrumen yang digunakan berupa lembar observasi untuk kegiatan open class dan lesson learned report.

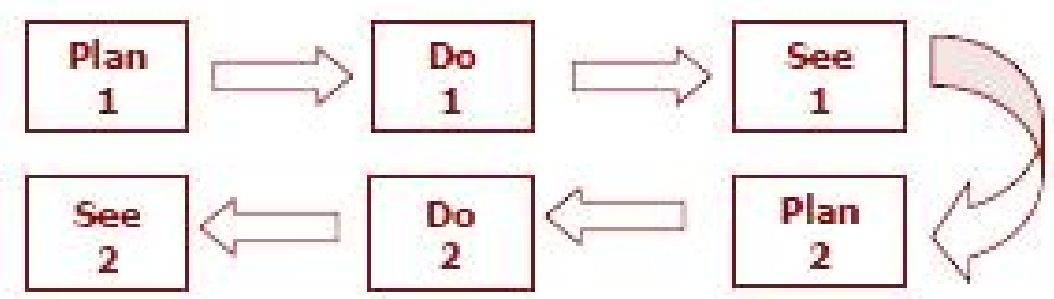

Gambar 3. Prosedur penerapan lesson study

\section{HASIL DAN PEMBAHASAN}

Siklus 1. Plan 1, tahap ini merencanakan desain lesson study dengan melibatkan 4 dosen di Program Studi Pendidikan Teknik Mesin. Hasil yang diperoleh adalah menentukan tujuan pembelajaran dan chapter desain lesson study untuk materi pengukuran menggunakan dial gauge. Tujuan pembelajaran yaitu (1) mahasiswa terampil dalam menggunakan dial gauge/dial indikator untuk mengukur komponen otomotif secara profesional dan akademik, (2) mahasiswa mengkomunikasikan hasil pengukuran melalui media online kepada teman sejawat. Sedangkan skenario chapternya menggunakan bahan ajar digital dengan software sigil dan readmed, mahasiswa diskusi prosedur penggunaan dial indikator dengan memanfaatkan referensi online dari 
bahan ajar digital, mempresentasikan hasil diskusi hingga diperoleh persamaan persepsi prosedur pengukuran sesuai SOP kemudian dilanjutkan praktik pengukuran dan mengupload hasil sharing prosedur pengukuran hingga didapat hasil di edmodo.
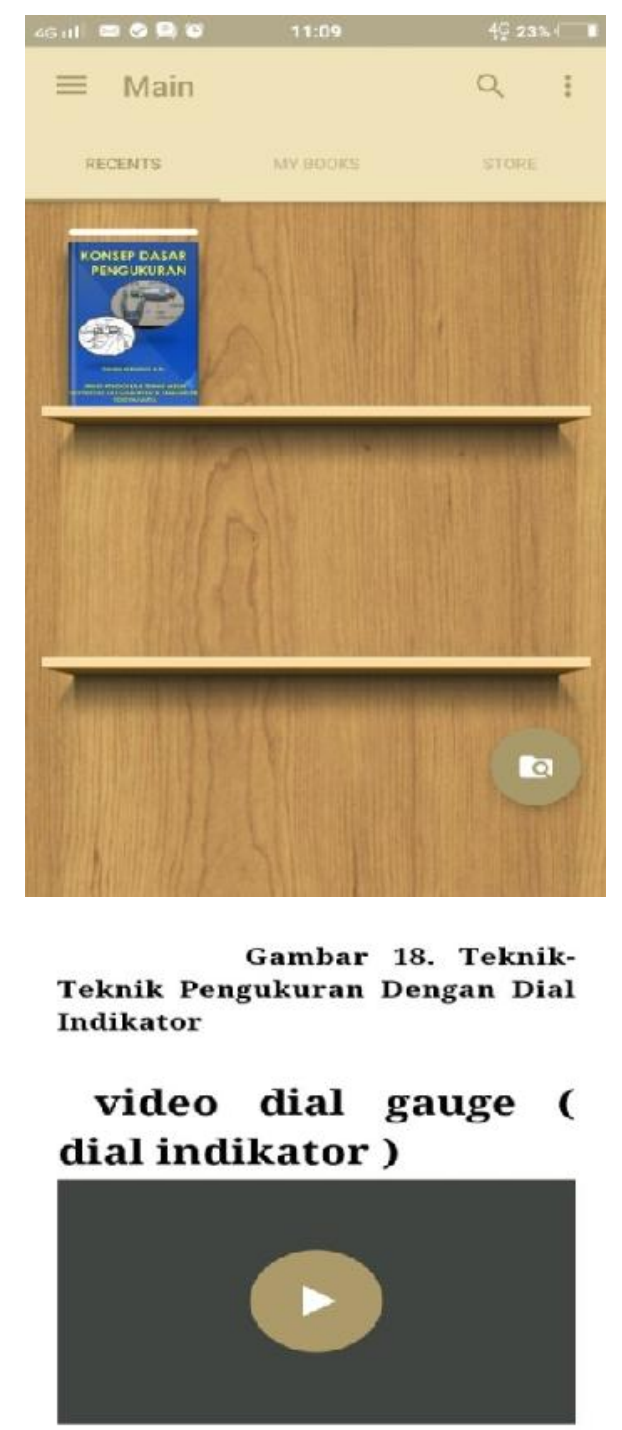

\section{Kaliper Pembagi (Cali- per Gauge)}

Gambar 4. bahan ajar digital

Do 1, open class pertama melibatkan 2 dosen sebagai observer. Kelas dibagi menjadi 6 kelompok dengan anggota masing-masing 5 mahasiswa. Kegiatan pembelajaran berlangsung selama 2.5 jam, dilakukan dengan praktik mengukur komponen kopling dan gardan dengan dial gauge dan pembuatan laporan secara lisan melalui record yang diunggah di edmodo. Observer secara berkeliling mengamati kegiatan praktik kelompok dan mengisi lembar observasi dan lesson learned report.

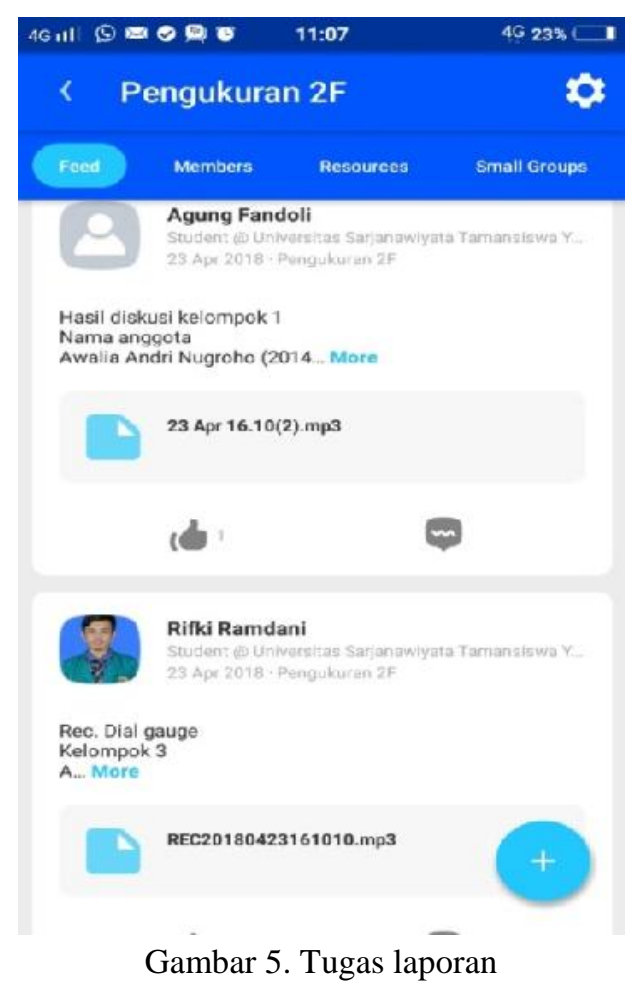

See 1, berdasarkan hasil pengamatan dosen model diperoleh temuan alokasi waktu kurang proporsional saat kegiatan record untuk upload di edmodo, kendala download bahan ajar pada memori mahasiswa ada 5 mahasiswa memori penuh, strategi pembelajaran efektif untuk meningkatkan keterampilan komunikasi. $60 \%$ mahasiswa aktif bertanya dan belajar dengan teman sejawat, sedangkan 12 mahasiswa lain masih cenderung pasif. Kecenderungan ini disebabkan karena mahasiswa bosan terlalu lama menunggu giliran praktik dan jaringan yang kurang suport. Sedangkan temuan observer, rata-rata mahasiswa dapat menggukur menggunakan dial indikator dengan benar serta dapat sharing 
tutorial penggunaan dial indikator dengan teman, pembagian waktu praktik perlu ditegaskan tiap mahasiswa agar tidak terjadi pemborosan waktu di anggota yang kurang terampil berkomunikasi, alat ukur perlu ditambah agar lebih proporsional rasionya. Belom 100\% mahasiswa yang benar-benar belajar.

Siklus 2. Plan 2, berdasarkan hasil refleksi pada tahap see 1 maka dilakukan revisi desain lesson study dengan 4 dosen pendidikan teknik mesin ust. Tujuan pembelajaran dirumuskan (1) mahasiswa terampil dalam menggunakan cylinder gauge untuk mengukur komponen otomotif secara profesional dan akademik, (2) mahasiswa mengkomunikasikan hasil pengukuran melaui mediaonline kepada teman sejawat. Sumber belajar yang digunakan tetap yaitu digital book, dan menerapkan e-learning, media pembelajaran praktik dengan menambahkan jumlah blok silinder dan sebagian kelompok langsung praktik di engine stand ny, waktu praktik ditentukan 5 menit untuk masing-masing siswa, pembuatan laporan praktik langsung di bengkel. Alat ukur yang digunakan cylinder gauge dan vernier caliper.

Do 2, kegiatan open class ke-2 adalah praktik mengukur menggunakan cylinder gauge dengan alat bantu calibrasi micrometer dan vernier caliper. Dosen model satu dan dua observer. Sedangkan instumennya berupa lembar observasi lesson study dan lesson learned report. Kelas dibagi menjadi 6 kelompok dengan anggota 5 mahasiswa. Mahasiswa diberi kebebasan belajar dengan anggota kelompok maupun antar kelompok lain. Tiap kelompok wajib membuat job description dan mengupload record prosedur penggunaan cylinder gauge sebagai laporan praktik.
See 2, temuan utama dosen model yaitu kegiatan belajar efektif, $94 \%$ mahasiswa dapat mengukur menggunakan cylinder gauge sesuai SOP dengan benar dan aktif sharing ilmu, memberikan masukan dan mengkonfirmasi tugas laporan kepada dosen. Keseluruhan mahasiswa dapat mengkomunikasikan informasi prosedur pengukuran dengan teman sejawat. 2 mahasiswa yang masih ada kesalahan dalam pembacaan skala sebaiknya ditempatkan pada urutan terakhir praktik. Sedangkan temuan dari observer yaitu mahasiswa terampil menggunakan cylinder gauge dengan benar dan bisa sharing ilmu tutorial penggunaan cylinder gauge sesuai pemahaman individu, dengan bahan ajar digital mahasiswa fokus membaca refensi, melalui record tutorial antar mahasiswa saling belajar dari teman satu sama lain. dua mahasiswa yang masih lemah dalam hal penghitungan skala cylinder gauge dikarenakan kesalahan baca alat ukur vernier kaliper.

Gambar 6 menunjukkan bahwa ada peningkatan jumlah mahasiswa yang aktif di kelas. Dimana yang semula hanya 6 mahasiswa yang mendominasi kelas sebelom dilaksanakan lesson study (20\%) meningkat $40 \%$ pada pelaksanaan open class pertama yaitu ada 18 mahasiswa(60\%) yang aktif dan $100 \%$ belajar selama kegiatan pembelajaran di bengkel. Lebih lanjut pada pelaksanaan open class kedua mengalami peningkatan signifikan menjadi 94\%(28 mahasiswa) yang aktif, dengan kata lain terjadi peningkatan 34\% dari siklus 1 ke siklus 2. Disamping berdampak pada peningkatan keaktifan mahasiswa, kegiatan lesson study berdampak positif pada keakuratan evaluasi hasil belajar mahasiswa. 


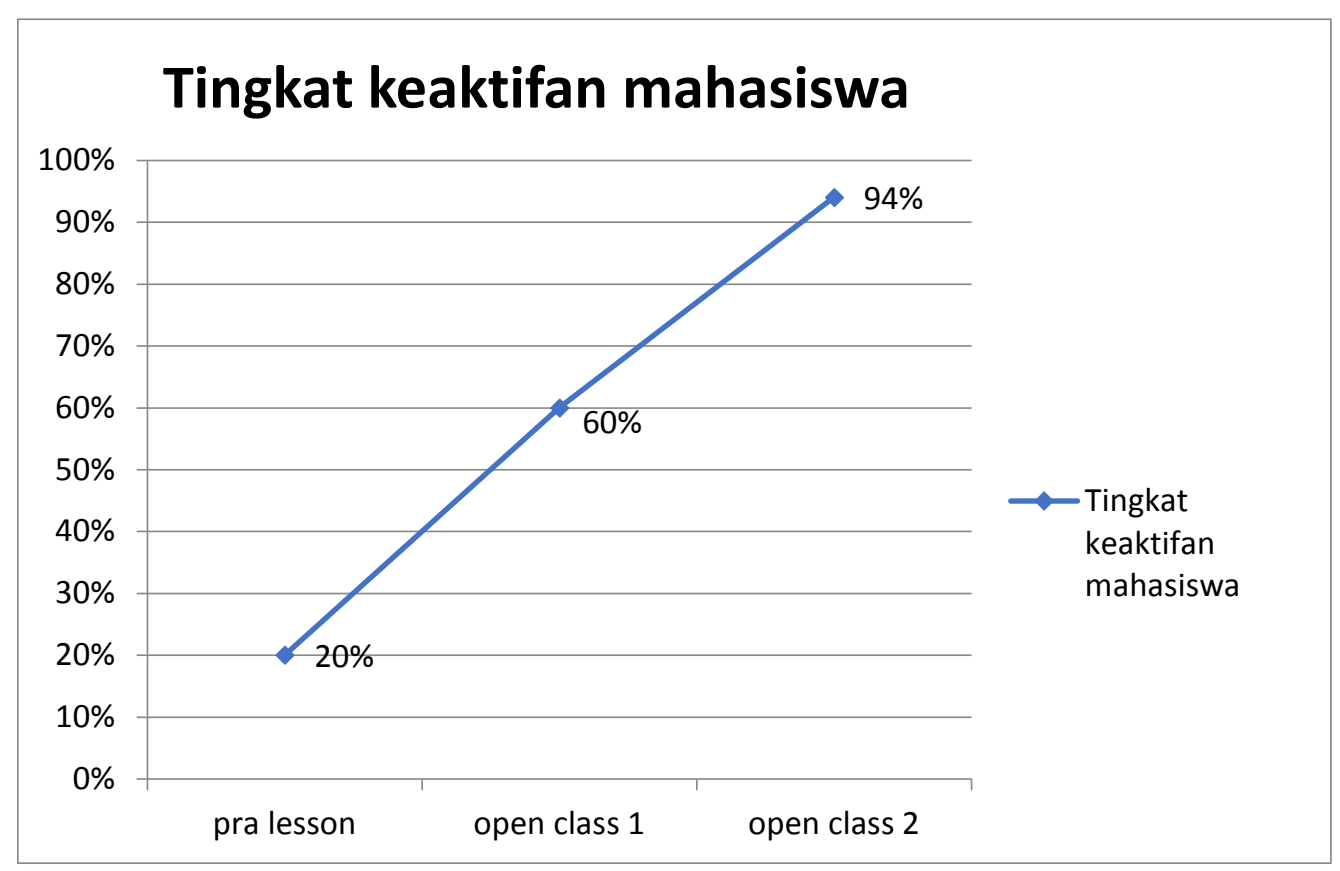

Gambar 6. Persentase tingkat keaktifan mahasiswa

Penilaian dosen menjadi lebih objektif dan transparan dikarenakan mendengarkan secara detail hasil laporan lisan tiap kelompok yang diunggah di edmodo, ditambah dari hasil observasi kegiatan praktik oleh dosen model yang dikuatkan dengan hasil pengisian lembar observasi dari dua observer dan hasil pengisian lesson learned report. Dari lembar observasi lesson study difokuskan pada kegiatan mahasiswa belajar, mengamati secara detail bagaimana mahasiswa belajar, siapa saja mahasiswa yang tidak belajar, mencari tahu penyebab mahasiswa tidak dapat belajar dengan baik, bagaimana cara dosen mendorong mahasiswa belajar sehingga hasil penilaian observer dapat digunakan untuk bahan refeensi perbaikan siklus berikutnya dan skaligus sebgaai validator penilaian terhadap mahasiswa. Sedangkan dari learned report diperoleh catatan penting hasil diskusi refleksi yang digunakan untuk redesain chapter lesson untuk siklus 2. Sedangkan dari pelajaran berharga di learned report dapat digunakan untuk lebih memahami kekurangan pembelajaran dan lebih memahami karakter peserta didik.

\section{SIMPULAN}

Kegiatan lesson study dengan pendekatan ICT memberikan dampak positif dalam memenuhi kebutuhan pendidikan di era 4.0. Esensi dari lesson study mampu meningkatkan keaktifan belajar mahasiswa dan membantu meningkatkan kualitas evaluasi/penilaian belajar bagi dosen untuk mahasiswa secara objektif, akurat, akuntabel, dan transparan.

\section{UCAPAN TERIMAKASIH}

Ucapan terimakasih, peneliti dedikasikan kepada Ditjen Sumber Daya IPTEK Dikti yang telah memberikan pelatihan Bimtek Lesson study bagi dosen baik banch 1 dan banch 2 . Sehingga ilmu yang didapat dapat langsung diterapkan di universitas dan berdampak dalam keberhasilan kegiatan penelitian.

\section{DAFTAR RUJUKAN}

Cerbin, W., dan Kopp, B. 2006. Lesson study as a Model for Building Pedagogical Knowledge and Improving Teaching. International Journal of Teaching and Learning in Higher Education, Volume 
18, Number 3, 250-257. ISSN 18129129. University of Wisconsin-La Crosse. (online) http://www.isetl.org/ijtlhe/

Hendayana, S., dkk. (2006). Lesson study: suatu Strategi untuk Meningkatkan Keprofesionalan Pendidikan (Pengalaman IMSTEP-JICA). Bandung : UPI Press.

Lewis, Catherine C. 2002. Lesson study: A Handbook of Teacher-Led Instructional
Change. Philadelphia, PA: Research for Better Schools, Inc.

Richardson, J. 2006. Lesson study: Teacher Learn How to Improve Instruction. Nasional Staff Development Council. (Online): www.nsdc.org. 03/05/06.

Saito, E., Imansyah, H. dan Ibrohim. 2005. Penerapan Studi Pembelajaran di Indonesia: Studi Kasus dari IMSTEP . Jurnal Pendidikan "Mimbar Pendidikan", No.3. Th. XXIV. 